\title{
Facilitating Transformation in Workforce Training: Using Clinical Theory to Understand Psychological Self-Sufficiency
}

\author{
Rana Hong \\ Loyola University Chicago, rhong1@luc.edu
}

Terry B. Northcut

Loyola University Chicago, tnorthc@luc.edu

Marcia Spira

Loyola University Chicago, mspira@luc.edu

Philip Young P. Hong

Loyola University Chicago, phong@luc.edu

Follow this and additional works at: https://ecommons.luc.edu/socialwork_facpubs

Part of the Social Work Commons

\section{Author Manuscript}

This is a pre-publication author manuscript of the final, published article.

\section{Recommended Citation}

Hong, Rana; Northcut, Terry B.; Spira, Marcia; and Hong, Philip Young P.. Facilitating Transformation in Workforce Training: Using Clinical Theory to Understand Psychological Self-Sufficiency. Smith College Studies in Social Work, 89, : 66-82, 2019. Retrieved from Loyola eCommons, Social Work: School of Social Work Faculty Publications and Other Works, http://dx.doi.org/10.1080/00377317.2019.1577046

This Article is brought to you for free and open access by the Faculty Publications and Other Works by Department at Loyola eCommons. It has been accepted for inclusion in Social Work: School of Social Work Faculty Publications and Other Works by an authorized administrator of Loyola eCommons. For more information, please contact ecommons@luc.edu.

\section{c) (†) $\ominus$}

This work is licensed under a Creative Commons Attribution-Noncommercial-No Derivative Works 3.0 License.

(c) Taylor \& Francis , 2019. 


\title{
Facilitating transformation in workforce training: Utilizing clinical theory to understand psychological self-sufficiency.
}

\begin{abstract}
Acknowledging the scarcity of a bottom up social work practice model in facilitating the development of success in workforce development programs, this study explores Psychological Self-Sufficiency (PSS) as an emerging social work practice theory. Phenomenological studies of low-income jobseekers in employment training along with the empirical validation of measures of Employment Hope and Perceived Employment Barriers resulted in the emergence of a new theory of PSS. PSS was conceptually defined as dynamic and internal drive that activates the process of transforming cognitively and affectively perceived barriers into hope driven action, enabled them to move forward. Based on the evidence of PSS, a participant-centered group intervention, called Transforming Impossible into Possible (TIP) program (Hong, 2016a; 2016b) was developed. This article delineates the trajectory of development of PSS theory by critically reviewing practice theories influencing PSS theory. Next, creating of TIP program and its core principles underlying the functions of PSS are explained. By depicting TIP program with direct quotes of clients' experiences, the authors successfully exemplify a self-discovery process of TIP program.
\end{abstract}




\section{PSYCHOLOGICAL SELF-SUFFICIENCY}

\section{Introduction}

Psychological self-sufficiency (PSS) is an emerging social work practice theory in direct contrast to many top-down practice models which aim to facilitate the development of success in human and social service programs. In appreciation of clients' phenomenological experiences and perceptions from their real-life accounts (i.e., "bottom-up") resulted in the development of the PSS model (Hong, 2013). PSS, as discussed in this article, emphasizes the need to explore and support the dynamic internal force (or energy) activated between acknowledging and experiencing perceived barriers and alternatively hope (Hong, 2016a). This dynamic process results in goal directed commitment and action by clients allowing them to be more successful as they return or enter the workforce. (Hong, 2013).

Traditionally, social work practice has borrowed and integrated a wide variety of theories and perspectives (Ayre \& Barrett, 2003; Howe, 1987; Johnsson \& Svensson, 2005; Payne, 1997; Sheafor \& Horejsi, 2006, 2012) to understand and describe the process by which individuals learn to function within their web of social systems. According to Sheafor \& Horejsi (2006), the main function of social work practice theory is "to explain certain human behaviors or situations, to guide intervention approaches, and to predict changes after applying its model" (p. 51). In other words, social work practice theories provide frameworks and explanations of human behavior (Johsson \& Svensson, 2005) to adequately guide practical approaches in order to best facilitate clients' 'process of facilitating growth and change' (Johnson \& Yanca, 2001, p.61). Inherent in many of these models is the understanding that change and growth is the result of a process between systems (individuals, groups, or organizations) rather than a single intervention administered to or on participants. PSS theory serves as a social work practice theory in that its theoretical constructs - perceived barriers and hope driven actions - account for clients' possible 


\section{PSYCHOLOGICAL SELF-SUFFICIENCY}

dysfunctional thought and behavioral patterns, guide the development of the intervention model called the Transforming Impossible into Possible (TIP) program ${ }^{1}$ (Hong, 2016a; 2016b), and predict how or what changes occur in the realm of individual functioning after applying the TIP intervention.

The PSS process can be described theoretically as being generated by a dynamic internal force that activates the process of cognitively and affectively transforming the perceived barriers into hope driven actions by which individuals become empowered to move forward toward achieving their goals (Hong, 2016a). This process of switching from barriers to hope is at the heart of the PSS theory (Hong, 2013; Hong, Choi, \& Key, 2018). Over the past decade, the theoretical constructs of PSS emerged from phenomenological studies of meaningful workforce development experiences of low-income jobseekers and service providers (Hong, 2013; Hong, Sheriff, \& Naeger, 2009). The original bottom-up theory-building process, which began in 2004, embodied Dr. Philip Hong's heuristic investigation and led to empirical research based on quantitative survey data obtained from more than 5,000 low-income individuals engaged in workforce development activities (Hong, Choi, \& Polanin, 2014; Hong, Hodge, \& Choi, 2015; Hong, Lewis, \& Choi, 2014; Hong, Polanin, Key, \& Choi, 2014; Hong, Polanin, \& Pigott, 2012; Hong, Song, Choi, \& Park, 2018; Hong, Stokar, \& Choi, 2016). Analysis and synthesis of the data resulted in the development of the Transforming Impossible into Possible (TIP) program (Hong, 2016a; 2016b). TIP is a group intervention model designed to strengthen one's PSS using a Person-In-Environment (PIE) framework applied to workforce development to create an inside out, bottom-up change model.

\footnotetext{
${ }^{1}$ TIP is an evidence-informed intervention model that is designed to strengthen one's PSS at the individual level and then to the outer layers of the system. It was developed by Dr. Philip Hong and his research team at the Center for Research on Self-Sufficiency in the School of Social Work of Loyola University Chicago in response to the need to empower the workforce development system from a Person-In-Environment (PIE) perspective.
} 


\section{PSYCHOLOGICAL SELF-SUFFICIENCY}

Currently, most workforce programs combine job training and employment opportunities to move individuals into the world of work. However, these programs are usually "top-down," "one-size fits all" attempts that can lead to frustration and wasted funding when individuals are not able to succeed in these programs, i.e., maintain sustained employment (Hong, 2013). Unfortunately, this macro approach misses what micro theories provide, the subjective context of the individuals and an understanding of how that context can either impede movement forward or facilitate that movement. In addition, the existing micro approaches-i.e., Supported Employment Programs (Blitz \& Mechanic, 2006)—only emphasize skill building training and/or collaborative case management services that insufficiently attend to the meaning of the subjective context of the individuals. To date, the majority of workforce development programs have not been able to provide a holistic clinical model that can help facilitate the development of success for participants.

Therefore, examination of PSS theory and the TIP intervention model is important for gaining insight into the constructed realities of individuals and the subsequent impact on effective service delivery in social work practice. In this regard, this article outlines some of the core principles of the TIP program and highlights emergent phenomena observed during TIP's implementation. Participants' experiences in the TIP program are illustrated through selected excerpts from qualitative interviews conducted with them and service providers in the TIP program at a non-profit agency in the Chicago area between 2014 and 2018.

\section{Development of PSS Theory}

The evolution of the PSS theory comes from an awareness that government funded job training programs are less effective in ending public assistance (Hamilton, 2002). The Personal Responsibility and Work Opportunity Reconciliation Act of 1996 (PRWORA; U.S. Public Law 


\section{PSYCHOLOGICAL SELF-SUFFICIENCY}

104-193) introduced self-sufficiency as a major goal of welfare reform, implying that it is a moral and functional duty of all U.S. citizens to work in order to support themselves and their families (Daugherty \& Baber, 2001). The ideological message in the Act is clear, but it hardly explains what self-sufficiency is and how it can be attained (Gowdy \& Pearmutter, 1993;

Bernstein, Brocht, \& Spade-Aguilar, 2000; Daugherty \& Baber, 2001). Generally speaking, the top-down definition of self-sufficiency offered by this policy is that a welfare recipient will leave the welfare rolls and replace the cash benefits with earned income through employment (Hong, Sheriff, \& Naeger, 2009). Self-sufficiency is mainly interpreted as economic self-sufficiency which then becomes the ESS measure of success in workforce programs. However, the sole criteria relied upon to define ESS is leaving welfare or public support and securing employment through which one can sustain an independent living with earned income. The subjective experiences of jobseekers get overlooked as a significant variable in understanding successes as well as failures in sustaining positive outcomes (Hong, 2013).

The concept of PSS arose when Hong, Sheriff, \& Naeger (2009) attempted to address this gap by performing qualitative focus group studies with jobseekers to understand more of their personal experiences in job readiness training programs. Qualitative results showed that participants described the process element of self-sufficiency—namely PSS—as more important than the outcome-based ESS (Hong, 2013). The two conceptual pillars of PSS rely on subjects' perceived employment barriers and the degree to which they are able to experience employment hope (Hong, 2013; Hong, Sheriff, \& Naeger, 2009). The Employment Hope Scale (EHS) and Perceived Employment Barrier Scale (PEBS) were quantitative studies developed and validated between 2010 and 2015 with over 5,000 individuals (Hong et al., 2016a; 2016b). EHS consists of four components that include psychological empowerment, futuristic self-motivation, 


\section{PSYCHOLOGICAL SELF-SUFFICIENCY}

utilization of skills and resources, and goal-orientation (Hong, Choi, \& Polanin, 2014) while PEBS consists of five factors namely physical/mental health, labor market exclusion, child care, human capital, and soft skills barriers (Hong et al., 2014). A theoretical path analysis confirms that perceived barriers to hope leads to ESS (Hong, Choi, \& Key, 2018). Based on phenomenological studies of low income jobseekers in employment training programs along with the empirical validation of measures resulted in the emergence of a new theory of PSS.

Conceptually, PSS refers to "a dynamic process of overcoming perceived employment barriers along the goal-oriented path to individualized success and development of employment hope within the new realities of career goals" (Hong et al., 2014, p.693). The PSS theory burgeons when explaining the subjective context of the individuals. Based on the PSS theory, insufficiently activated PSS as a process - known as the transforming power from the perceived barriers (impossible) into hope actions (possible) — is the root of identified barriers and blockages as they rise to the surface of human functioning. It means that the alleviation of barriers and blockages may occur if sufficient PSS is activated through natural human practice or by applying an intervention such as TIP. PSS theory suggests that an individual could move forward toward achieving goals even in the face of the realities of pressing personal and/or structural barriers, an example of activated PSS (Hong, 2016a).

Based on PSS research, there are two distinctive but interchangeable PSS processes that occur: the explicit process (cognitive process) and the implicit process (non-cognitive process) to create the transforming force (Hong et al., 2014). Whilst some aspects of vocational theories like the Social Cognitive Career Theory (SCCT; Lent, Brown, \& Hackett, 1994; 2002) and clinical psychology theories like Positive Psychology (Seligman, 1991) and the Mental Contrasting with Implementation Intention (MCII; Oettingen \& Gollwitzer, 2010) explain the explicit process of 


\section{PSYCHOLOGICAL SELF-SUFFICIENCY}

PSS, the underlying transforming qualities are rooted in the implicit processes of PSS. . The initial stage of the individual transformation seems to rely on the naming of and "radically accepting" perceived negative constraints. ${ }^{2}$ These include the recognition of internal and external employment barriers that disrupt the development of employment hope which cannot exist outside of the context of a critical relationship (Hong, 2014). It is in the context of relational change that the group process enables participants to accept themselves and potentiate self-efficacy, leading to PSS (Hong, Lewis, \& Choi, 2014).

The explicit process of PSS is informed by SCCT and MCII, but sufficient differences exist. For instance, SCCT provides a construct of vocational hope (Brown et al., 2013), similar to employment hope in PSS. SCCT treats barriers as a contextual factor and suggests that the interplay between hope-related self-efficacy and outcome expectations lead to vocational hope, while PSS theory posits that employment hope is activated by sharing the vulnerability associated with perceived barriers in a relational context (Hong, 2016a). In this regard, 'shared vulnerability' is a crucial concept in PSS theory since it (shared vulnerability) helps individuals to keep moving forward with hope-driven actions. PSS also embraces optimistic goal-directed cognitions similar to those suggested in positive psychology (Seligman, 1991). Like some of the tenets of positive psychology, individuals need to be encouraged to approach rather than avoid goals and find the internal strengths that are personally and culturally meaningful to them.

However, PSS theory does not aim at distancing the person from adverse outcomes. Rather, PSS suggests uncovering the perceived barriers that would lead to discovering the pathway to hope (Hong, Hong, \& Williams, 2018). While process is of high importance in PSS theory, the

\footnotetext{
2 Similar to the radical acceptance employed in Dialectical Behavior Therapy developed by Marsha Linehan (e.g., 2014), however not meant to be associated with any particular identified psychopathology or group of disorders. PSS shares with DBT an emphasis on and understanding of the Buddhist ideology of accepting what is present in the "here-and-now".
} 


\section{PSYCHOLOGICAL SELF-SUFFICIENCY}

outcome is given stronger emphasis in positive psychology. MCII is an approach that helps an individual attain a future outcome by contrasting the obstacles of the reality that stand in the way and form strategies to reach the desired future (Oettingen, 2000). MCII puts a heavy weight on only cognitive functioning, but PSS theory differs in that it requires integrative connections between cognitive-emotional-sensory functioning to make the PSS process blossom.

The implicit 'process' as posited by PSS theory is supported by relational theory which provides the core root from which corollaries and postulates stem. According to Borden (2000), a relational perspective balances the consideration of various domains while also honoring core social work beliefs: "first, the inherent capacities of persons for growth and change; second, the complexity and interdependence of human relationships and social life; and the third, the role of the professional relationship in the process of change" (p. 370). As such, one needs to clearly understand the nature of personalized interactions with social environments and work environments through a relational framework to more fully grasp what facilitates the unique individual success processes in workforce development. At the heart of the relational framework lies the transformative power of relationships which can utilize and transform prior, internalized, and codified schematic experiences into current and future relationships which enable them to succeed in the work world. To better enhance workforce development programs, it is important to first understand how those past and current relationships get codified.

The relational approach assumes a postmodern perspective that is inherently contextual and subjective. Modifying the anticipation of negative responses from individuals in power works to increase the repertoire of responses of individuals to authority. Consequently, what may have been experienced by employees as barriers to success can be re-contextualized and responded to more productively. According to relational theory, the intrapsychic structures 


\section{PSYCHOLOGICAL SELF-SUFFICIENCY}

evolve from cognitive and affective experiences that create templates relied upon in any interpersonal interaction as a means to negotiate complex and overwhelming stimuli, referred to as 'intersubjectivity' (Berzoff, 2016). Facilitating transformative relationships supports the development of the necessary executive abilities or self-regulating functions, traditionally known as ego functions. Skills similar to mentalization or the ability to perceive oneself and others (Fonagy, 2002) combined with positive imagery or the ability to envision the desired outcome of an interaction (Conoley, Plumb, Hawley, Spaventa-Vancil Hernandez, 2015) are necessary to augment the development and experience of PSS. Some of the most essential skills required of new employees rely on the ability to engage flexibly in a dynamic process with the environment to accurately perceive stimuli, respond appropriately, and develop a felt sense of competency in that process (expanding the historical ego psychological concepts of reality testing, judgment, and impulse control). Unfortunately, data from employers in workforce programs indicate that common problems occurring in returning to work usually have to do with interpersonal difficulties and problem solving when confronted with tension points in the workplace (Carnochan, Taylor, Pascual, \& Austin, 2014). Individuals who retain basic assumptions that interpersonal relationships are based on power and control or who have had negative interpersonal interactions are probably less likely to succeed in the work environment. Years of adverse encounters in hostile or depressed environments naturally result in mistrust of the intentions of others and resistance to attempts at intervention. Patterned responses developed in individuals who have repeatedly experienced negative reactions may come to expect these responses from all encounters. The narrative of self-defeat can only be weakened in the context of consistent relational experiences within the self and the power of shared vulnerability with others who refuse to reenact the past. Without the PSS process, employees' ability to 


\section{PSYCHOLOGICAL SELF-SUFFICIENCY}

successfully negotiate complex work environments and sustain hope toward long-term job retention and advancement in the workforce is reduced. The critical question remains: what is the process that can transform the subjective experiences of individuals so that they can more effectively function in the workplace. The "cure" rests on the development of PSS which helps protect against the vulnerability in relationships - a vulnerability that built up over time from repeated experiences of social and economic failure which led to a pervasive sense of hopelessness about gaining employment.

Intra-personal transformation can only occur, however, in the presence of current facilitative relationships with 'shared vulnerability' that can evoke past supportive templates, as scarce as they may have been. Wachtel (2011) envisions a process of cyclical psychodynamics that attest to the reciprocal reinforcement of negative interactions. Individuals are active participants in the completion of negative interpersonal interactions and relations, as well as in the establishment of new, positive interpersonal relationships. Pozutto and Caddigan (2009) affirm that a relational perspective is consistent with reciprocal influences and the co-creation that results from interactions with one's environment. Within this relational framework, individuals are not only viewed as victims of environmental insufficiencies but retain the capacity to influence possible outcomes, i.e., individual sense of agency (Martin \& Sugarman, 1999). This environment can provide the necessary reflection and response to enable individuals to move from perceiving insurmountable barriers to successful employment by hopeful movement forward. One potential goal of workforce development programs, then, is to understand, educate, and potentially alter the intrapsychic structures that previously resulted in negative outcomes by replacing those narratives of hopelessness with new narratives of possibility in the relational context. Figure 1 shows the relationships among the key constructs 


\section{PSYCHOLOGICAL SELF-SUFFICIENCY}

found in the PSS theory and its 'TIPPING' process - the conceptual PSS process as applied in practice using the TIP (Transforming Impossible into Possible) model.

[Insert Figure 1 about here]

\section{Creation of Transforming Impossible into Possible (TIP) Program}

Based on the evidence of PSS, a participant-centered group intervention model called Transforming Impossible into Possible (TIP) was developed by Dr. Philip Hong and his research team at the Center for Research on Self-Sufficiency (CROSS) at Loyola University Chicago School of Social Work (Hong, 2016a; 2016b). As stated earlier, PSS theory was developed through a practice-informed research and TIP created as an evidence-informed intervention model that is designed to strengthen one's PSS, building on the Person-in-Environment (PIE) framework. It was recognized as one of the top five evidence-informed innovative socioemotional training programs in workforce development for a low-income population by the Mathematica Policy Research in a report published by The U.S. Department of Health and Human Services, Administration for Children and Families (ACF)/Office of Planning, Research, and Evaluation (OPRE) (Anderson, Brown, Cavadel, Derr, \& Kauff, 2018).

TIP is a model that begins with the individual's transformation from the "inside out" to the outer layers of the system (Hong, 2016a). It is based on 15 sessions of personal discovery group modules designed to attend to individuals' existential meaning as it relates to the pursuit of a goal-i.e., employment. While linearly introduced, the 9 themes and 15 topics in TIP are recursively interrelated: (1) Identity and purpose [TIP 1: Who am I / purpose in life]; (2) forgiveness [TIP 2: self-compassion]; (3) goal-orientation [TIP 3: Goal setting; TIP 4: Improvement and pathways (1)]; (4) barriers [TIP 5: Barriers inventory]; (5) source of strength [TIP 6: My strength comes from]; (6) employment hope [TIP 7: Love \& self-worth; TIP 8: Self- 


\section{PSYCHOLOGICAL SELF-SUFFICIENCY}

perceived capability; TIP 9: Future and the possibilities; TIP 10: Self-motivation; TIP 11: Skills and resources inventory; TIP 12: Renewed goal commitment / improvement and pathways (2)]; (7) unresolved triggers of stress and anger [TIP 13: Managing stress and anger]; (8) gratitude [TIP 14: Finding meaning in life]; and (9) social support and compassion [TIP 15: Seeking help and helping others]. To date, the intervention model has been applied to facilitate the transition from chronic unemployment to employment, retention, and career advancement, and it is being applied in the areas of homelessness, fatherhood and family strengthening, financial literacy, and youth empowerment.

Described extensively in prior research (Hong, 2016a, 2016b, Hong et al., 2016, Hong et al., 2018), TIP attempts to provide the scaffolding needed for individuals, from the "bottom-up" to successfully negotiate the difficulties that typically develop when participating in the labor market. However, the focus on the individual does not obscure the need to change the social and economic structures that contribute to unemployment (Hong, 2014, Hong, Hodge, \& Choi, 2015). But without acknowledgement that there are individuals with unique histories and experiences within these workforce programs, it is easy to ignore an important resource for success: The person. The TIP program is distinguished by the attention directed to the individuals as well as the environment (Hong, 2016a).

The program acknowledges that barriers in the environment (poverty, insecure housing, lack of education, disruptive family dynamics) act upon the individual and may feed the negative self-concept and thoughts about the individual's capacity to succeed. The environmental determinants impinge upon the individual's view of themselves and may squelch the motivation to move forward in the employment process. In addition, past personal or witnessed failures of attempts to gain leverage in the job market may lead to hopelessness. Hopelessness, in turn, 


\section{PSYCHOLOGICAL SELF-SUFFICIENCY}

produces negative behaviors which serve to reinforce negative reactions in the workplace. The TIP program focuses on the development of PSS which takes both external barriers as well as internal challenges into account to disrupt negative interpersonal interactions. Transforming Impossible into Possible (TIP) is one such program which embraces the importance of relationships to facilitate the development and maintenance of PSS.

The group dynamic that develops among participants in the TIP program is one of the essential ingredients in the firm establishment of a renewed sense of self and PSS. Irving Yalom's list of "curative factors" has provided the standard set of universal principles that describe how groups create positive change (Yalom, 1995). Each of the therapeutic factors supports a relational dynamic. The therapeutic factors include interpersonal connection (that provide affirmation and promote the development of empathy), interpersonal learning (imparting information of how to interact with others and the consequences of interactions), universality (individual problems not alone) instillation of hope (identifying with the successes of others and believing in the possibility of achievement), and catharsis (individual learns to express their needs, emotions and perceived barriers). Through the impact of interaction in the group, these factors describe the opportunities for the group participants to connect with one another and gain strength through the development of relationships. The therapeutic factors are not assumed to naturally occur without navigating through a terrain of risk-taking and establishment of trust. The success of the TIP program rests on the potential impact of the relationships within the group to disrupt the negative narratives carried by members and to re-narrate stories of hope and success. Excerpts from interviews with TIP participants and facilitators vividly describe the PSS process.

\section{Experience with TIP Program to Date}

Every class we started off with putting our barriers on red card, and towards the end, it requested that we got to fill out two green cards with our hope- how we are going to 


\section{PSYCHOLOGICAL SELF-SUFFICIENCY}

overcome our barriers. I would say for the first five or six weeks, every week I had the same barrier -which was having a criminal background and being an African American male. Then I started to realize this is not a barrier, you know, because it is nothing I can change. I can't change my criminal background; I can't change for being an African male. So, going to the TIP process, I figured more my barrier is not an African male, I just got to know how to deal with it. So, I figured out how to deal with it by going to the TIP program. Just last week, I was offered a job with my background and so went off my experience of working because what I learned was that I had to sell myself who I am, not who I was and what I can bring to a company. Judge me off of who I am and who I will be, not off of who I was. So, the more and more I kick down the door, try to kick down the barrier and overcome it, I figure out that, my barrier isn't that I am an African American. My barrier is- how do I overcome that." (TIP Talks ${ }^{3}$ from a graduate of the TIP program in August 2017)

The PSS journey in TIP typically begins with the PSS surveys that are administered at three time points - beginning, middle and end of program participation. Participating in the PSS survey is the starting point for the reflective process that will continue through the course of TIP and "keep the PSS engine running." While the survey serves the purpose of gathering the data that can be monitored throughout program participation, the self-administered nature of it allows participants to create their baseline for individual transformation. The role of TIP facilitators' is to guide and model the individual and group PSS processes, albeit with one major qualification, they must be an acknowledged participant observer, not an "outside" recorder of the process. The TIP facilitators role of participant observer does not limit his or her responsibility for creating safety through a therapeutic alliance. The TIP facilitators warm, authentic, and empathic presence is a prerequisite to deepen the PSS processes. It is imperative to establish with the group that all group members, including the facilitator, are the leaders in their own lives and are necessary agents to transform barriers to hope (PSS). This emphasis lays the foundation for transforming an external locus of control in the area of job success, to an

\footnotetext{
3 TIP Talks is the success story of TIP program participants who best practice TIPPING barriers to hope (psychological self-sufficiency),
} 


\section{PSYCHOLOGICAL SELF-SUFFICIENCY}

internal locus of control particularly in the area of ability to secure employment and/or opportunities that may still exist even in an oppressive social environment. We know that it is common and inevitable for members of disadvantaged populations who are especially vulnerable to external environmental factors to experience themselves as unable to have an impact on their immediate economic world. By positioning themselves as participants, group leaders emphasize and demonstrate that all members can have an impact on their economic and interpersonal narrative even while recognizing as the participant did in the example above, that some characteristics do not change, but what the individual can do with those factors can change.

Facilitators in TIP programs provide self-monitoring with group members to acknowledge the impact of being a member of the group and avoiding the "us" vs "them" mentality common in top-down workforce programs. As with any relational therapeutic model, recognizing the subjective experiences of facilitators does not mean extensive unwarranted disclosures of personal information. With the TIP facilitator training, which constitutes a two day long TIP experiential program engaging in an array of reflective and integrative activities as active participants and an additional two-day long didactic program participating in lectures and discussions, TIP facilitators are able to reflect within the groups their self-observations as they relate to the ongoing process of transforming awareness into action, i.e., accessing an internal locus of control to achieve external behavioral changes. They must resist the temptation to use a regimented toolkit. The potential injurious consequences to participants could be profound and only following the scripted group facilitation can overlook the need for individual attention. In the TIP program, facilitators are more apt to use their own experiences in an empathic and reciprocal appreciation of the challenges in gaining and sustaining employment that has been stimulated in the ongoing group dynamic. 


\section{PSYCHOLOGICAL SELF-SUFFICIENCY}

As one facilitator reported:

I certainly do not have an answer. It would be a lie on my part to pretend like I know what is best for each group member. It is only when I shared my experiences as someone who similarly does not have it all together all of the time, and who lacks confidence and is scared to face the realities of this world, were participants able to empathize with me and then tell their own stories. They were invested in my story, and I was in turn invested in theirs. We wanted to be part of rewriting each other's stories to one of success and hope or at least one that is on the right path to success even when confronted with overwhelming obstacles. I am a beneficiary by having been part of the same PSS journey with other TIP participants - just with a different kind of story.

Postmodernism, fortunately, has pushed us to appreciate that neither a therapist nor a facilitator is the "editor" of the participant's story (Northcut, 2000) rather co-creators with other participants in their individual and group stories.

TIP relies on the development and capacity for self-reflection while being part of a therapeutic group that attempts to help each other find his or her answers to common existential questions (e.g., Who am I? Where do I come from? Where am I going? What is the purpose in life?). Participants learn there are no wrong answers to these questions based on the valued uniqueness of each individual story and life trajectory. Often "clients" or group members present themselves with a clear, biased subjective experience of their own shortcomings, failures, mistakes, losses, etc. By normalizing the existence of self-perceived and realistic external barriers, these perceived barriers to success can act as a trigger to identify next steps that would move the individual into a commitment to hopeful actions.

At first the participants may not be able to face themselves with the reflective questions. Some participants sit quietly just thinking about the questions and do not write anything in the workbook. They often respond that they have never been asked these questions ever before. They claim that people do not typically count them in when it comes to co-writing the outcome of their life story. TIP invites them to a different place in their lives, to be the leading actors who do not 


\section{PSYCHOLOGICAL SELF-SUFFICIENCY}

only react to life challenges but proactively create positive actions that further develop positive

opportunities and outcomes in life. As reported by one participant:

I just go with the flow like everyone else in the community. There's nothing there for us. The wealth and opportunities are for White people. We just got the dead-end situation. We kill each other and go to prison. We have to hustle and work the streets to be able to find the money to pay for things. Why should I care about doing better? All I got is three strikes on my record, and nobody wants a criminal to work for them. It's the same old story. But I am no longer defined by my past failures. Everyone has problems. We are humans. But we are also very blessed with the gift to make things beautiful out of nothing. I never had goals in life, but I now really want to do better. I want to give back to my community and keep young people from joining the gangs. I will create hope of everything around me that makes me feel down. I am beautiful not in spite of but because of my scars.

Often the social structure and workforce systems remind people of the things they are not good at rather than the things they do well. By framing these "deficits" as "barriers" group members can normalize them as diverse life situations often faced by most everyone, albeit at differing levels of intensity and perniciousness. As the participants in the TIP intervention model, they are asked to challenge each other to not dwell in their experiences of the barriers, but to create a constant motion of positive, "hopeful," actions to overshadow the barriers with hope. In an authentic sense TIP is an empowerment, strengths-based intervention model, however, there is a necessary, internal process that must be emphasized as well. Cognitive restructuring (Wright, Basco, \& Thase, 2006) can only occur with the simultaneous investment in group relationships scaffolding an environment of acceptance, challenge, and then growth.

In the majority of participants, an important significant other whether living, deceased, close or estranged, serves as a tipping point from focusing on barriers to hope. It is the representation of that relationship that is cognitively restructured as a strength. As group members provide a cognitive reframing of internalized negative perceptions of each member's capacity and life course, the relational inner PSS process is targeted as well. It is the focus on this 


\section{PSYCHOLOGICAL SELF-SUFFICIENCY}

internal process that allows the "TIPPING" of barriers to hopeful actions by being anchored and invigorated by the sources of strength that one can draw from in their lives.

When Dr. Philip Hong asked us to list the sources that can help tip the barriers to hope, I started thinking of my grandmother, mother, sister, children, and others who are still fighting the fight with me to keep things moving toward a better tomorrow. We may be struggling now but there is not nobody or nothing that's going to stop us from going forward. I am all about hope. On my low days, TIP has reminded me to think about my grandmother's voice, "You are the most beautiful person. God loves you so much and always remember that. He will never let you down." And I will not let them down—God, my grandmother, and all the people I love. They are my sources of energy. I keep on holding on to my hope.

The main goal of the TIP model is to enhance individuals' PSS skills through various praxis activities (i.e., reflection plus action, and engagement in transformative group). By targeting individualized goals, TIP allows participants to engage in a self-discovery process that allows them to identify strengths within themselves and in their environment that then facilitates transforming their perceived barriers to hope. While many workforce development or adult education staff have been trained to be TIP facilitators, the role of clinical social workers in TIP implementation is immense. Not only could clinical social workers expand some therapeutic use of the TIP program for individuals, but they might also be the best candidates for trainers of TIP facilitators. Specific protocols for requiring the proper level of training and experience to become TIP trainers are in the process of development.

\section{Conclusion}

Employment stability is one goal that transcends political ideology or professional disciplines. Extensive study has confirmed for researchers and clinicians alike that our brains allow us to change and evolve over time, while simultaneously establishing connections that can make it very difficult to change cognition, behavior and affect. We also know from clinical experience that we co-create with clients their narratives that allow them to be empowered to 


\section{PSYCHOLOGICAL SELF-SUFFICIENCY}

reshape their narrative as they move forward. Engagement in powerful positive relationships has the potential to reshape narratives of failure to stories of hope and possibility. In this regard, the theory of PSS emerged from qualitative and quantitative research which appears to offer a path to transform individuals from anticipating failure to processes that lead to workforce success. The implications for workforce development require that the PSS process is helping individuals to be aware of and embrace the perceived negative aspects of their lives and careers as well as envisioning the positive. Indeed, the development of PSS has the potential to facilitate growth. The maturation of a balanced, "healthy" PSS acknowledges vulnerability and facilitates recognition and strength from past interpersonal interactions. Considering a belief in the possibility of change despite the reality of obstructive forces is the fundamental tenet of solid, strengths based social work, PSS theory and its associated TIP model offer a new possibility of change by "helping people to discover the power within themselves to recognize and overcome barriers and develop intrinsically motivational hope" (Hong, 2016b, p. 10). For one to fully undergo the PSS process, the switch from perceiving the negative employment barriers to engendering hope, an ability to have goals for the future and plans for how to meet these goals, needs to take place in order to empower jobseekers to move towards a path of employment with economic security (Hong, 2014). As a result, one may begin the process of a reconciliation between negative and positive experiences, to construct a more realistic self-appraisal.

In order to continue to build evidence of the effectiveness of TIP model, the dynamic between the relational inner PSS process with the external experiences needs to be further explored. What are the mechanisms by which the switching from perceived barriers to hopeactions help guide a successful pathway to attain goals? How is a personal narrative reconstructed to allow for a different outcome than what an individual has experienced in the 


\section{PSYCHOLOGICAL SELF-SUFFICIENCY}

workplace in the past? As with any study of the dynamic process occurring between individuals and their new work environments, more research is needed to understand fully how these processes can be used to more fully enhance the experiences of individuals and of groups. 


\section{References}

Ayre, P., \& Barrett, D. (2003). Theory and practice: the chicken and the egg. European Journal of Social Work, 6(2), 125-132.

Bernstein, J., Brocht, C., \& Spade-Aguilar, M. (2000). How much is enough? Basic family budgets for working families. Washington, DC: Economic Policy Institute.

Berzoff, J. (2016). Inside out and outside in: Psychodynamic clinical theory and psychopathology in contemporary multicultural contexts $\left(4^{\text {th }}\right.$ eds. $)$. Rowman \& Littlefield Publishers.

Borden, W. (2000). The relational paradigm in contemporary psychoanalysis: Toward a psychodynamically informed social work perspective. Social Science Review, 74(3), 352379.

Blitz, C. L., \& Mechanic, D. (2006). Facilitators and barriers to employment among individuals with psychiatric disabilities: A job coach perspective. Work, 26, 407-419.

Brown, S. D, Lamp, K, \& Telander, K .J, (2013), Career development as prevention: toward a social cognitive model of vocational hope. In E. M. Vera (Ed.), The Oxford handbook of prevention in counseling psychology. New York: Oxford University Press (pp.374-392).

Carnochan, S., Taylor, S., Pascual, G., \& Austin, M. (2014). Employer perspectives on the role of soft skills in subsidized employment relationships. Families in Society: The Journal of Contemporary Social Services, 95, 187-194.

Conoley, C.W., Plumb, E.W., Hawley, K.J., Spaventa-Vancil, K.Z., \& Hermándex, R.J. (2015). Integrating positive psychology into family therapy: Positive family therapy. The Counseling Psychology, 43(5), 703-733.

Daugherty, R.H., \& Barber, G.M. (2001). Self-sufficiency, ecology of work, and welfare reform. Social Service Review, 75(4), 662-675.

Fonagy, P., Gergely, G.; Jurist, E.; Target, M. (2002). Affect Regulation, Mentalization, and the Development of the Self. NY: Other Press.

Gowdy E and Pearlmutter S, 1993, Economic self-sufficiency: It's not just money. Affilia, 8, 368-387.

Hamilton, G. (2002, July). Moving people from welfare to work: Lessons from the national evaluation of welfare-to-work strategies. Manpower Demonstration Research Corporation. Retrieved November 19, 2006, from http://aspe.hhs.gov/hsp/NEWWS/synthesis02/. 
Hong, P.Y.P. (2013). Toward a client-centered benchmark for self-sufficiency: Evaluating the 'process' of becoming job ready. Journal of Community Practice, 21, 356-378.

Hong, P.Y.P. (2014). Employment hope: A path to empowering disconnected workers. In E. J. Clark \& E. F. Hoffler (Eds.), Hope matters: The power of social work (pp.143-148). Washington, D.C.: NASW Press.

Hong, P. Y. P. (2016a). Transforming Impossible into Possible (TIP): A bottom-up practice in workforce development for low-income jobseekers. Environment and Social Psychology, 1, 93-104.

Hong, P.Y.P. (2016b). Learning to TIP: Introduction. Chicago, IL: Center for Research on SelfSufficiency (CROSS) Loyola University Chicago.

Hong, P.Y.P. \& Choi, S. (2013). The employment hope scale: Measuring an empowerment pathway to employment success. International Journal of Psychology Research, 8, 173189.

Hong, P.Y.P., Choi, S., \& Key, W. (2018). Psychological self-sufficiency: A bottom-up theory of change in workforce development. Social Work Research, 41(1), 1-11.

Hong, P.Y.P., Choi, S., \& Polanin, J.R. (2014). A multi-sample confirmatory factor analysis of the Short Employment Hope Scale (EHS-14). Journal of Social Service Research, 40, $339-352$.

Hong, P. Y. P., Hodge, D., \& Choi, S. (2015). Spirituality, hope, and self-sufficiency among low-income job seekers. Social Work, 60, 155-164.

Hong, P.Y.P., Hong, R., \& Williams, D. (2018). Psychological self-sufficiency (PSS) as a success process in health profession career pathways. Paper presented at the Fourteenth International Congress of Qualitative Inquiry. Champaign-Urbana, IL, May 17-19.

Hong, P.Y.P., Lewis, D., \& Choi, S. (2014). Employment hope as an empowerment pathway to self-sufficiency among ex-offender. Journal of Offender Rehabilitation, 53, 317-333.

Hong, P.Y.P., Song, I., Choi, S., \& Park, J.H. (2016). A cross-national validation of the Employment Hope Scale in the U.S. and South Korea. Social Work Research, 40(1), 4151.

Hong, P.Y.P., Song, I., Choi, S., \& Park, J.H. (2018). Comparison of perceived employment barriers among low-income jobseekers in the United States and South Korea. International Social Work, 61, 23-39.

Hong, P.Y.P., Stokar, H., \& Choi, S. (2016). Psychological and economic self-sufficiency among low-income jobseekers with physical disability barriers. Environment and Social Psychology, 1(1), 63-73. 
Hong, P.Y.P., Polanin, J.R., Key, W., \& Choi, S. (2014). Development of the Perceived Employment Barrier Scale (PEBS): Measuring psychological self-sufficiency. Journal of Community Psychology, 42, 689-706.

Hong, P.Y.P., Polanin, J.R., \& Pigott, T.D. (2012). Validation of the employment hope scale: Measuring psychological self-sufficiency among low-income jobseekers. Research on Social Work Practice, 22, 323-332.

Hong, P.Y.P., Sheriff, A., \& Naeger, S. (2009). A bottom-up definition of self-sufficiency: Voices from low-income jobseekers. Qualitative Social Work, 8, 357-376.

Howe, D. (1987). An Introduction to Social Work Theory. Hant, England: Wildwood House.

Johnsson, E. \& Svensson, K. (2005). Theory in social work-Some reflections on understanding and explaining intervention Teori I social arbete-några reflektioner om att förstå interventioner, European Journal of Social Work, 8(4), 419-433.

Johnson, L.C., Yanca, S.J. (2001). Social work practice: a generalist approach (7th eds.). MA: Pearson Education.

Lent, R. W., Brown, S. D., \& Hackett, G. (1994). Toward a unifying social cognitive theory of career and academic interest, choice, and performance [Monograph]. Journal of Vocational Behavior, 45, 79-122.

Linehan, M. M. (2014). Dialectical Behavioral Therapy Skills Training Manual. NY: Guildford Press.

Lent, R. W., Brown, S. D., \& Hackett, G. (2002). Social cognitive career theory. Career Choice and Development, 4, 255-311.

Martin, J. \& Sugarman, J. (1999). The Psychology of Human Possibility and Constraint. NY: SUNY Press

Northcut, T. B. (2000). Constructing a place for religion and spirituality in psychodynamic practice. Clinical Social Work Journal Vol. 28, No. 2, 155-169.

Oettingen, G. (2000). Expectancy effects on behavior depend on self-regulatory thought. Social Cognition, 18, 101-129.

Oettingen, G., \& Gollwitzer, P. (2010). Strategies of setting and implementing goals: Mental contrasting and implementation intentions. In J.E. Maddux \& J.P. Tangney (Eds.), Social psychological foundations of clinical psychology (pp. 114-135). New York: Guilford Press.Payne, M. (1997). Modern Social Work Theory ( $2^{\text {nd }}$ Eds), Chicago: Lyceum Books

Pozutto, R., Arnd-Caddigan, M. \& Averett, P. (2009). Notes in support of a relational social work perspective: A critical review of the relational literature with implications for macro practice. Smith College Studies in Social Work, 79, 5-16.

Sheafor, B.W. \& Horejsi, C.R. (2012). Techniques and Guidelines for Social Work Practice $\left(9^{\text {th }}\right.$ Eds). Boston: Pearson Education. 


\section{PSYCHOLOGICAL SELF-SUFFICIENCY}

Seligman, M. E. P. (1991). Learned optimism. New York: Knopf.

TIP Talks: Wisdom for Humanship 1. Available at https://www.youtube.com/watch?v=ylQ62T2MXqM\&index=2\&list=PLnLrvjkpJourAsn MmCyF8P_8lu3v4hLno

Anderson, M. A., Brown, E., Cavadel, E. W., Derr, M., \& Kauff, J. F. (2018). Using psychologyinformed strategies to promote self-sufficiency: A review of innovative programs (OPRE Report \#2018-41). Washington, D.C: Office of Planning, Research and Evaluation, Administration for Children and Families, U.S. Department of Health and Human Services. Available at https://www.acf.hhs.gov/opre/resource/using-psychologyinformed-strategies-to-promote-self-sufficiency-a-review-of-innovativeprograms?utm_source=facebook\&utm_medium=social\&utm_campaign=general

Wachtel, P. (2011) Therapeutic Communication: Knowing what to say when. $\quad\left(2^{\text {nd }}\right.$ ed.). NY: Guilford

Wright, J. H., Basco, M. R., \& Thase, M. E. (2006). Learning cognitive-behavior therapy: An illustrated guide. Washington, D. C.: American Psychiatric Publishing Inc.

Yalom, I. D. (1995). The theory and practice of group psychotherapy ( $4^{\text {th }}$ Eds). NY: Basic Books 
Figure 1. Diagram of relationships among PSS constructs and TIPPING

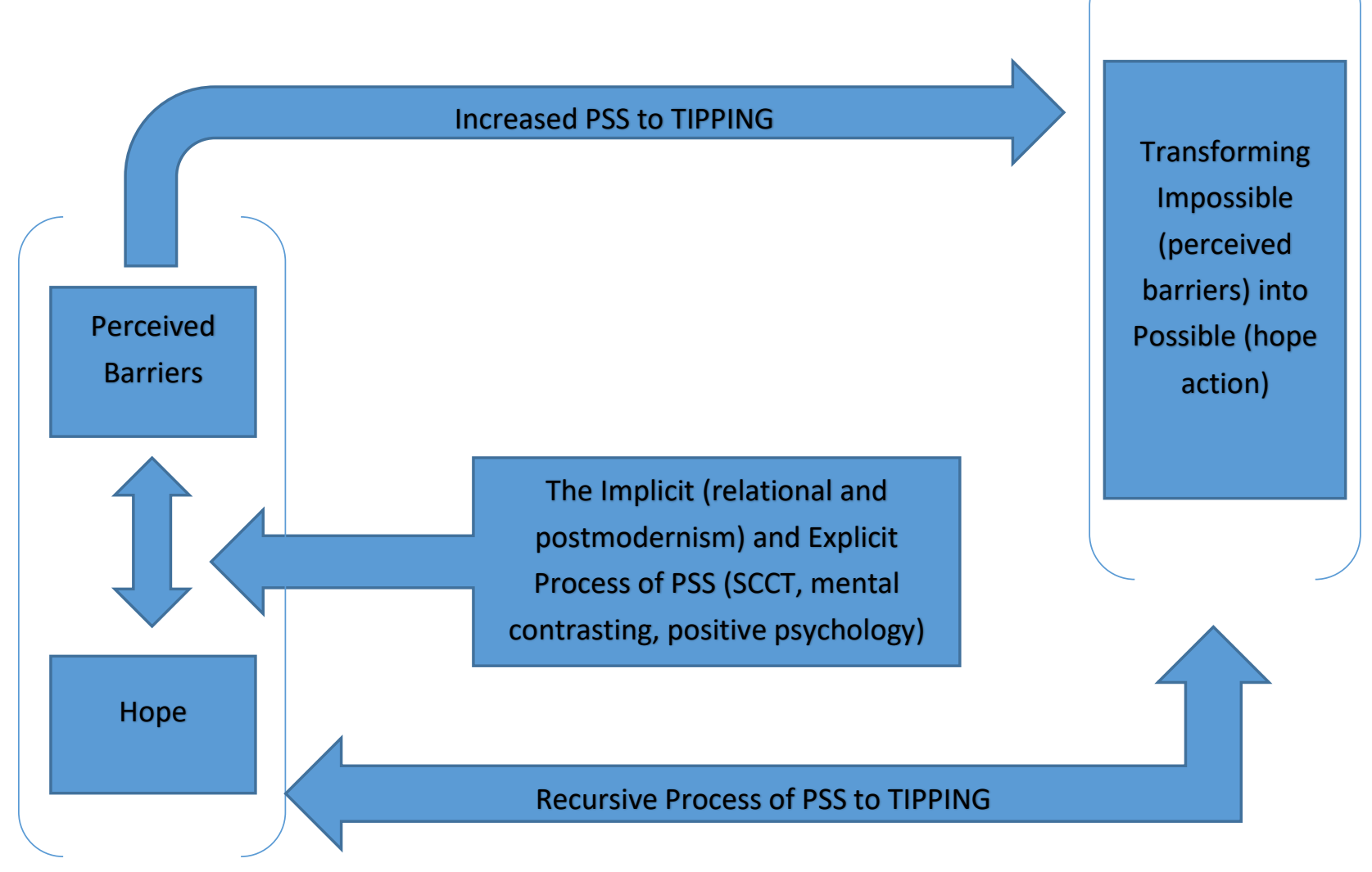

